\title{
The Association Between Prolonged Proton Pump Inhibitors Use and Bone Mineral Density
}

This article was published in the following Dove Press journal:

Risk Management and Healthcare Policy

\author{
Mohammad Reza Fattahi ${ }^{\prime}$ \\ Ramin Niknam (1) \\ Mesbah Shams (iD ${ }^{2}$ \\ Amir Anushiravani ${ }^{3}$ \\ Seyed Alireza Taghavi iD ${ }^{\prime}$ \\ Gholamhossein Ranjbar \\ Omrani ${ }^{2}$ \\ Laleh Mahmoudi (iD ${ }^{4}$ \\ 'Gastroenterohepatology Research \\ Center, Shiraz University of Medical \\ Sciences, Shiraz, Iran; ${ }^{2}$ Endocrine and \\ Metabolism Research Center, Shiraz \\ University of Medical Sciences, Shiraz, \\ Iran; ${ }^{3}$ Digestive Disease Research \\ Institute, Shariati Hospital, Tehran \\ University of Medical Sciences, Tehran, \\ Iran; ${ }^{4}$ Department of Clinical Pharmacy, \\ School of Pharmacy, Shiraz University of \\ Medical Sciences, Shiraz, Iran
}

Correspondence: Ramin Niknam Gastroenterohepatology Research Center, Shiraz University of Medical Sciences, Shiraz 7|935-I3II, Iran $\mathrm{Tel} / \mathrm{Fax}+98-7 / 3-6276212$

Email niknamramin@yahoo.com
Background and study aim: Chronic use of proton-pump inhibitors (PPIs) has become a mainstay of therapy in common gastrointestinal diseases. A causal relationship between chronic PPI use and development of osteoporosis remains unproven. The aim of this study was to determine whether PPI users are more likely to develop alterations in bone density.

Patients and methods: In an analytical cross sectional study, patients who used PPIs for more than 2 years because of long-term gastroesophageal reflux disease (GERD) were recruited. PPI users were healthy people except for GERD. The compression group was randomly derived from an age-, sex- and physical activity-matched group from a healthy population in the National Registry of Osteoporosis who had not used PPIs in the previous 2 years. Bone mineral density was measured with dual-energy X-ray absorptiometry. Data regarding $\mathrm{BMD}$ and bone mineral content $(\mathrm{BMC})$ of three regions: femoral neck, total hip, and the lumbar spine (L1-L4) were gathered and recorded. The World Health Organization (WHO) classification was used for definition of osteopenia and osteoporosis.

Results: A total of 394 participants (133 PPI users and 261 comparison group) were enrolled. The median duration of PPI use was 6.7 (2-31) years. The mean age \pm SD of PPI users and comparison group was $48.38 \pm 11.98$ and $47.86 \pm$ years, respectively $(\mathrm{P}=0.681)$. There was no significant difference in baseline characteristics and age distribution between the two groups. The BMC levels were significantly lower in PPI users in all three regions: lumbar spine, total hip, and femoral neck $(\mathrm{P}<0.001)$. There were no significant differences in the T-scores between the two groups except for femoral neck $(\mathrm{P}<0.001)$. Osteoporosis in femoral neck was significantly higher in PPI users than in comparison group.

Conclusion: This study showed that long-term use of PPIs is associated with lower BMC and higher rate of osteoporosis in the femoral neck. However, more studies with longitudinal evaluation should be performed to clarify this causal relationship. Until then, it is advised not to overuse PPIs because of the possible increase in risk of osteoporosis and the risk of fractures. We also recommend using the BMC levels as a quantitative measure in addition to $\mathrm{T}$ scores in analysis and reporting similar studies.

Keywords: proton pump inhibitors, bone density, osteoporosis, dyspepsia, metabolic bone diseases

\section{Introduction}

The use of proton pump inhibitors (PPIs) has escalated since 2003, after US Food and Drug Administration approval. Their use in 2002 and 2009 were $4.0 \%$ and $9.2 \%$ in the outpatient setting, respectively. ${ }^{1}$ Chronic PPI use has become a mainstay of therapy in a number of common medical conditions such as gastroesophageal reflux 
disease (GERD), peptic ulcers, dyspepsia, and prevention of drug-induced peptic ulcers. ${ }^{2}$

PPIs are generally considered safe, but recent studies have shown that chronic PPI use increases the risk of decreased bone density. ${ }^{3-5}$ However, a causal relationship between chronic PPI use and development of osteoporosis and fractures remains unproven. There is controversy about this topic in previous studies. Although some researchers have found no significant association between long-term use of PPIs and adverse effects on bones, ${ }^{4,-9}$ on the other hand, other studies have found a moderate or even significant association. $^{5,10-12}$ Given the widespread use of PPIs in the community and the controversy about adverse effects of prolonged PPI use on bone density, we designed this study.

The aim of this study was to determine whether longterm PPI users versus non-users are more likely to develop alterations in dual-energy X-ray absorptiometry (DXA) derived bone mineral density (BMD).

\section{Methods}

\section{Participants}

In this analytical cross-sectional study, all consecutive adult patients with long-term use of PPIs because of long-term GERD referred to the gastroenterology clinic, which is the main referral center in Shiraz, South of Iran, affiliated to Shiraz University of Medical Sciences, from June 2015 to March 2019, were recruited. PPI users were healthy people except for GERD. We defined long-term PPI users as those with $\geq 2$ years consumption of medication. In order to compare PPI users group with a PPI non-users group, we used block randomization method to select age-, sex- and physical activity-matched group from healthy population in the National Registry of Osteoporosis. PPI non-users group consisted of healthy participants who had not used PPIs in the previous 2 years. The exclusion criteria of both groups were pregnancy, lactation, alcoholism, use of any medication, low vitamin D levels (25-OH Vitamin D3 $<20 \mathrm{ng} / \mathrm{mL}$ measured with HPLC method), history of a fracture, systemic and/or metabolic diseases (including thyroid, parathyroid, rheumatic disease, diabetes mellitus, etc.), co-morbid disorders (including liver, kidney, heart, lung, malignancy, etc.), and uncooperative patients. The patients with abnormal BMD were also evaluated by an endocrinologist to exclude those with secondary causes of decreased BMD.

A checklist of both groups was filled out by an interviewer, who was trained prior to the initiation of the study; including baseline characteristics, past medical history, personal and family history, medication use, and physical activity. Physical activity was classified as high grade if the participant walked at least 30 mins three times a week or run at least 30 mins two times per week, moderate if he/ she walked between 15-30 mins for between 1-3 times a week or run at least 30 mins one time per week, and low grade if they met none of the above criteria.

\section{Dual-Energy X-Ray Absorptiometry}

BMD (g/cm2) and bone mineral content (g) were measured [Hologic Discovery DXA System, Bedford, MA, USA] for all participants by a trained technician under the supervision of an endocrinologist. Data regarding BMD and bone mineral content (BMC) of three regions; femoral neck, total hip, and the lumbar spine (L1-L4) were gathered and recorded. The World Health Organization (WHO) classification was used for definition of osteopenia (T-score: between -1.0 and -2.5 ) and osteoporosis (T-score $\leq-2.5$ ). Based on the preliminary measurements in ten participants, the coefficients of variations in this system were $2.4 \%$ for the femoral neck BMC and $0.51 \%$ for the lumbar spine.

\section{Statistical Analysis}

Quantitative variables were compared between PPI users and non-users groups using an independent sample $t$-test. Chi-squared test was used to compare the qualitative variables. We used ANOVA test to compare mean BMCs and mean T-scores in subgroup analysis according to physical activity and duration of PPI use. Pearson's correlation coefficient was used to determine the relationship between T scores and duration of PPI use. A $P$ value of $<0.05$ was considered statistically significant.

\section{Ethical Approval/Statement}

This study was conducted following the declaration of Helsinki regarding ethical principles for medical research. Institutional review board committee approval was obtained from the Shiraz University of Medical Sciences Ethics Committee (92-01-13-5648). Written informed consent was obtained from all participants.

\section{Results}

A total of 394 participants were enrolled in this study, 133 were long-term PPI users and 261 had not used PPIs in the last two years. The mean age \pm SD of PPI users and comparison group was $48.38 \pm 11.98$ and $47.86 \pm 11.61$ years, respectively $(\mathrm{P}=0.681)$. Baseline characteristics are shown in Table $1.90 .3 \%$ of PPI users reported using PPIs once daily. 
The duration of PPI use ranged from 2-31 years, with a median of 6.71 years. As shown in Table 1, there was no significant difference in baseline characteristics between the two groups. The age distribution of the PPI users and comparison groups is shown in Table 2. There was no significant difference in age distribution between the two groups.

Table 3 shows the results of DXA-derived BMD and BMC in both groups. The BMC levels were significantly lower in PPI users than PPI non-users in all three regions; lumbar spine (L1-L4), total hip, and femoral neck $(P<0.001)$. There were no significant differences in the T-scores between the two groups except for that of the femoral neck $(P<0.001)$. Z-scores did not show a significant difference in any of the regions.

Physical activity was established in the participants, dividing them into three groups of high, moderate, and low grade activity. Table 4 shows the effect of physical activity on DXA-derived BMD and BMC in the PPI users. No significant differences were seen in BMC of PPI users regarding their physical activity.

Table I Baseline Characteristics of Enrolled Proton-Pump Inhibitors (PPI) Users and PPI Non-users

\begin{tabular}{|l|l|l|l|}
\hline Variables & $\begin{array}{l}\text { PPI Users } \\
\text { (n=I33) }\end{array}$ & $\begin{array}{l}\text { PPI Non-Users } \\
\text { (n=26I) }\end{array}$ & P Value \\
\hline $\begin{array}{l}\text { Age* (years) } \\
\text { Female sex (\%) }\end{array}$ & $48.38 \pm 11.98$ & $47.86 \pm 11.61$ & 0.681 \\
$\begin{array}{l}\text { Body mass index * } \\
\left(\text { Kg/m }{ }^{2}\right)\end{array}$ & $26.11 \pm 4.44$ & 25.5 & 0.860 \\
$\begin{array}{l}\text { Smoking (\%) } \\
\text { PPI used once }\end{array}$ & 10.8 & 9.9 & 0.253 \\
$\begin{array}{l}\text { daily (\%) } \\
\text { PPI used twice } \\
\text { daily (\%) }\end{array}$ & 90.3 & 0 & 0.475 \\
\hline
\end{tabular}

Notes: *Mean \pm Standard deviation; test: independent sample $t$-test.

Table 2 Age Distribution in Proton-Pump Inhibitor (PPI) Users and PPI Non-users

\begin{tabular}{|l|l|l|l|}
\hline & PPI Users (\%) & PPI Non-Users (\%) & P Value \\
\hline $\begin{array}{l}\text { Age (years) } \\
<30\end{array}$ & $6(4.5)$ & $16(6.1)$ & \\
$30-39$ & $25(18.8)$ & $46(17.6)$ & 0.5122 \\
$40-49$ & $39(29.3)$ & $86(33.0)$ & 0.7694 \\
$50-59$ & $38(28.6)$ & $67(25.7)$ & 0.4556 \\
$60-69$ & $21(15.8)$ & $40(15.3)$ & 0.5383 \\
$>70$ & $4(3.0)$ & $6(2.3)$ & 0.8967 \\
Total & $133(100)$ & $261(100)$ & 0.6760 \\
\hline
\end{tabular}

Table 3 Comparison of Dual-Energy X-Ray AbsorptiometryDerived Bone Mineral Density and Bone Mineral Content (BMC) Between Proton-Pump Inhibitor (PPI) Users and PPI Non-users

\begin{tabular}{|l|l|l|l|}
\hline Variables* & $\begin{array}{l}\text { PPI Users } \\
(\mathbf{n}=1 \mathbf{3 3})\end{array}$ & $\begin{array}{l}\text { PPI Non-Users } \\
(\mathbf{n}=26 \mathrm{I})\end{array}$ & $\begin{array}{l}\text { P } \\
\text { Value }\end{array}$ \\
\hline $\begin{array}{l}\text { Lumbar spine } \\
\text { BMC }\end{array}$ & $0.92 \pm 0.24$ & $1.05 \pm 0.17$ & $<0.00 \mathrm{I}$ \\
$\begin{array}{l}\text { Lumbar spine } \\
\text { T-Score }\end{array}$ & $-1.20 \pm 2.17$ & $-1.10 \pm 1.38$ & 0.59 \\
$\begin{array}{l}\text { Lumbar spine } \\
\text { Z-Score }\end{array}$ & $-0.48 \pm 2.09$ & $-0.71 \pm 1.23$ & 0.19 \\
$\begin{array}{l}\text { Total hip BMC } \\
\text { Total hip T-Score }\end{array}$ & $-0.82 \pm 0.12$ & $0.94 \pm 0.12$ & $<0.001$ \\
$\begin{array}{l}\text { Total hip } \\
\text { Z-Score }\end{array}$ & $-0.09 \pm 0.88$ & $-0.53 \pm 1.06$ & 0.49 \\
$\begin{array}{l}\text { Femoral neck } \\
\text { BMC }\end{array}$ & $0.70 \pm 0.11$ & $0.87 \pm 0.13$ & 0.37 \\
Femoral neck & $-1.3 \pm 1.03$ & $-0.84 \pm 1.08$ & $<0.001$ \\
$\begin{array}{l}\text { T-Score } \\
\text { Femoral neck } \\
\text { Z-Score }\end{array}$ & $-0.65 \pm 0.85$ & $-0.84 \pm 1.08$ & $<0.001$ \\
\hline
\end{tabular}

Note: *Mean \pm Standard deviation.

A Pearson's correlation was used to determine the relationship between $\mathrm{T}$ scores and duration of PPI use. There was a significant positive relationship between duration of PPI usage and BMC of the lumbar spine (L1-L4). There was no significant relationship between duration of PPI and BMC and T score of femoral neck and hip usage (Table 5). PPI users were divided in 3 categories according to the duration of use and the BMCs and T-scores were compared with ANOVA test (Table 6).

We also compared the frequency of osteopenia and osteoporosis between PPI users and non-users using chisquared tests, summarized in Table 7. The group of PPI users included more patients with osteopenia/osteoporosis that is significant in femoral neck region.

\section{Discussion}

This study assessed the influence of long-term PPI use on bone mineral density in three regions (lumbar spine (L1L4), total hip, and femoral neck), and found a significantly lower BMC in all three regions in PPI users of more than 2 years duration compared with those whom had no history of PPI use within the previous 2 years.

The results of this study support the meaningful connection between long-term PPI use and development of bone-related adverse health outcomes, such as osteoporosis. The WHO has classified low bone mineral density into 
Table 4 Dual-Energy X-Ray Absorptiometry-Derived Bone Mineral Density and Bone Mineral Content (BMC) in Proton-Pump Inhibitor (PPI) Users According to Physical Activity ( $\mathrm{N}=133)$

\begin{tabular}{|c|c|c|c|c|}
\hline \multirow[t]{2}{*}{ Variables* } & \multicolumn{3}{|c|}{ Grade of Physical Activity** in PPI Users } & \multirow[t]{2}{*}{ P Value } \\
\hline & High $(n=65)$ & Moderate $(n=35)$ & Low $(n=33)$ & \\
\hline Age (years) & $48.12 \pm 13.23$ & $48.49 \pm 12.00$ & $48.78 \pm 9.26$ & 0.97 \\
\hline Body mass index $\left(\mathrm{Kg} / \mathrm{m}^{2}\right)$ & $26.90 \pm 4.78$ & $24.79 \pm 3.30$ & $25.91+4.56$ & 0.07 \\
\hline Lumbar spine (LI-L4) BMC & $52.61 \pm 24.42$ & $53.26 \pm 10.34$ & $54.90 \pm 13.97$ & 0.79 \\
\hline Lumbar spine (LI-L4) T-Score & $-1.13 \pm 2.81$ & $-1.47 \pm 1.13$ & $-1.08 \pm 1.4 \mid$ & 0.35 \\
\hline Lumbar spine (LI-L4) Z-Score & $-0.34 \pm 2.69$ & $-0.80 \pm 1.16$ & $-0.4 I \pm 1.30$ & 0.56 \\
\hline Total hip BMC & $30.25 \pm 7.91$ & $30.12 \pm 5.81$ & $30.39 \pm 9.08$ & 0.06 \\
\hline Total hip T-Score & $-0.58 \pm 1.05$ & $-0.69 \pm 0.81$ & $-0.60 \pm 1.05$ & 0.16 \\
\hline Total hip Z-Score & $-0.13 \pm 0.92$ & $-0.22 \pm 0.75$ & $-0.11 \pm 0.93$ & 0.66 \\
\hline Femoral neck BMC & $3.63 \pm 0.76$ & $3.50 \pm 0.51$ & $3.7 I \pm 0.92$ & 0.27 \\
\hline Femoral neck T-Score & $-1.37 \pm 1.11$ & $-1.49 \pm 0.85$ & $-1.30 \pm 1.07$ & 0.27 \\
\hline Femoral neck Z-Score & $-0.61 \pm 0.87$ & $-0.77 \pm 0.72$ & $-0.60 \pm 0.97$ & 0.46 \\
\hline
\end{tabular}

Notes: *Mean \pm Standard deviation; test: ANOVA test. **Physical activity was classified as high grade if the participant walked at least 30 mins three times a week or run at least 30 mins two times per week, moderate if he/she walked between 15-30 mins between I-3 times a week or run at least 30 mins one time per week, and low grade if they met none of the above criteria.

Table 5 Correlation of Duration of Proton-Pump Inhibitor Use with Dual-Energy X-Ray Absorptiometry-Derived Bone Mineral Content $(B M C)$ and $T$ Scores $(N=133)$

\begin{tabular}{|l|l|l|}
\hline Variables* & $\mathbf{r}$ & P Value \\
\hline Lumbar spine T-score & 0.153 & 0.08 \\
Lumbar spine BMC & 0.209 & 0.02 \\
Total hip T-score & -0.023 & 0.79 \\
Total hip BMC & -0.003 & 0.97 \\
Neck of femur T-score & -0.007 & 0.94 \\
Neck of femur BMC & 0.035 & 0.69 \\
\hline
\end{tabular}

Note: *Test: Pearson's correlation.

three groups: osteopenia, osteoporosis, and severe osteoporosis (T-score $\leq-2.5$ with history of fracture). We found that although those with chronic PPI use had significantly lower BMC levels in all three regions, according to the WHO criteria the BMDs were not significantly different in lumbar spine (L1-L4) and total hip region. It was only significantly different in the femoral neck, showing that chronic PPI use may be associated with falls in the WHO category of osteopenia/osteoporosis.

The US Food and Drug Administration issued a warning in 2010:

possible increased risk of fractures of the hip, wrist, and spine with high doses or long-term use of a class of medications called proton pump inhibitors. The product labeling will be changed to describe this possible increased risk. (US. FDA News Release, May 25, 2010)

Several potential mechanisms have been proposed linking PPIs and increased fracture risk including malabsorption of calcium due to hypochlorhydria, gastrin-induced parathyroid hyperplasia, and osteoclastic vacuolar proton pump inhibition. ${ }^{3}$

The influence of long-term PPI use on BMD and indices of bone strength between persons using PPIs for more than 5 years was not significant in a study on 104 subjects (52 cases and controls). They concluded that no meaningful

Table 6 Dual-Energy X-Ray Absorptiometry-Derived Bone Mineral Density in Proton-Pump Inhibitor (PPI) Users According to the Duration of PPI Use ( $N=133)$

\begin{tabular}{|l|l|l|l|l|l|}
\hline \multirow{2}{*}{ Variables* } & \multicolumn{2}{l|}{ Duration of Use of PPI } & \multirow{2}{*}{ P Value } & \multirow{2}{*}{ Post Hoc Tukey } \\
\cline { 2 - 5 } & 2-5 Years (n=69) & 5-10 Years (n=37) & > 10 Years (n=27) & & \\
\hline Age (years) & $45.68 \pm 12.60$ & $50.00 \pm 10.24$ & $52.80 \pm 11.03$ & 0.02 & I vs. III \\
Body mass index (Kg/m $\left.{ }^{2}\right)$ & $25.99 \pm 4.94$ & $26.94 \pm 3.75$ & $25.53 \pm 3.92$ & 0.44 & - \\
Lumbar spine (LI-L4) T-Score & $-1.33 \pm 1.11$ & $-1.40 \pm 1.53$ & $-0.46 \pm 4.25$ & 0.19 & - \\
Total hip T-Score & $-0.60 \pm 0.92$ & $-0.57 \pm 1.10$ & $-0.66 \pm 1.04$ & 0.94 & - \\
Femoral neck T-Score & $-1.36 \pm 0.95$ & $-1.43 \pm 1.16$ & $-1.36 \pm 1.08$ & 0.95 & - \\
\hline
\end{tabular}

Notes: *Mean \pm Standard deviation; test: ANOVA. 
Table 7 Frequency of Osteopenia/Osteoporosis* in ProtonPump Inhibitor (PPI) Users and PPI Non-users

\begin{tabular}{|l|l|l|l|}
\hline Variables** & $\begin{array}{l}\text { PPI Users } \\
\text { (n=133) }\end{array}$ & $\begin{array}{l}\text { PPI Non-Users } \\
\text { (n=26 I) }\end{array}$ & P Value \\
\hline $\begin{array}{l}\text { Lumbar spine } \\
\text { osteopenia (\%) } \\
\text { Lumbar spine } \\
\text { osteoporosis (\%) } \\
\text { Femoral neck } \\
\text { osteopenia (\%) } \\
\text { Femoral neck } \\
\text { osteoporosis (\%) }\end{array}$ & 43.9 & 39.7 & 0.44 \\
\hline
\end{tabular}

Notes: *The World Health Organization classification was used for definition of osteopenia (T-score: between -1.0 and -2.5 ) and osteoporosis (T-score $\leq-2.5$ ). **Test: Chi-squared.

connection between long-term PPI use and bone-related adverse effects was seen. ${ }^{6}$ A nested case control study in the United Kingdom General Practice Research Database including over 44,000 cases and almost 11,000 controls revealed that the risk of hip fractures did not increase in the absence of major risk factors. ${ }^{4}$ Three case control studies were evaluated by Laine L., in which two of them showed a small but significant association between PPIs and fractures, and a third showed a modest significant association after 7 years of continuous PPI use. This study concluded that any increase in fracture risk with chronic PPI use, if present, would be of relatively low magnitude. ${ }^{10} \mathrm{~A}$ prospective case control study on patients using PPIs for at least 6 months demonstrated a significant reduction in vertebral and femoral T-scores, measured by densitometry. ${ }^{5} \mathrm{~A}$ systematic review and meta-analysis with over 200,000 fracture cases showed a modest association between PPI use and increased risk of hip and vertebral fractures, but duration had no effect in subgroup analysis. ${ }^{11}$ Our study showed a significant positive relationship between duration of PPI usage and BMC of the lumbar spine. But the duration of PPI use had no significant effects on femoral neck and hip. Although the BMC levels were significantly lower in PPI users in all three regions, the reason for the significant effects of PPI use on the T-scores of femoral neck but not on the lumbar spine is unclear in our study. Further research is needed to answer this question.

Population-based samples of Canadians with over 8000 subjects were enrolled from the Canadian Multicentre Osteoporosis Study data set. BMD was checked at baseline and 5 and 10 years later and they found that PPI users had lower BMD at baseline, but PPI use more than 10 years was not associated with accelerated loss in BMD. ${ }^{7}$
Khalili et al conducted a prospective cohort in the 11 most populous states in America and showed that during 565,786 person years of follow-up, chronic use of PPIs was associated with increased risk of hip fracture, especially in women with a history of smoking. ${ }^{12}$ Adachi et al ${ }^{13}$ compared bone mineral density in $\mathrm{H} 2$ receptor antagonist (H2RA) users over 2 years and healthy controls and found little non-significant influence on the degree of BMD. Solomon et al conducted a study to show the association between annualized BMD changes and new use of PPIs in pre- or early menopause women. They showed no significant association between the use of new PPIs and BMD loss. ${ }^{14}$ In a clinical trial study of postmenopausal women by Hansen et al, they showed a significant increase in markers of bone turnover in the PPI user group (26 weeks) compared to placebo, but levels remained within the normal reference range. They showed no significant differences between the two groups in BMD, levels of parathyroid hormone, serum or urine levels of minerals, or true fractional calcium absorption. ${ }^{15}$

We found that in comparison to an age- and sexmatched normal population group, PPI users had similar rates of osteopenia/osteoporosis in the lumbar spine (L1L4), but osteoporosis in femoral neck of PPI users was significantly higher than comparison group. The mean age of our participants was young. The reason was probably due to the strict inclusion and exclusion criteria to eliminate other confounding and risk factors of osteoporosis.

The previously mentioned studies that reported the effects of gastric-acid suppressants on the bone health used the WHO classification for low bone density as a semi-quantitative measure. The WHO recommends calculation of T-score with a uniform, standardized reference database in men and women of all ethnic groups, using the National Health and Nutrition Examination Survey (NHANES) III database for femoral neck measurements in young-adult Caucasian women. ${ }^{16}$ The international Society for Densitometry (ISCD) Official Position on this issue was changed to be concordant with the WHO recommendation, in 2013. The recommendation of both organizations being a uniform Caucasian (non-race adjusted) female normative database for women and men of all ethnic groups. ${ }^{17}$ It should be noted, that application of the above recommendation may vary according to local requirements and most DXA systems currently in clinical use continue to report T-scores in males using a male reference database. DXA system manufacturers should use NHANES III Caucasian data as the reference for 
femoral neck and total hip T-scores, while continuing to use their own databases for the lumbar spine as the reference standard for T-scores. ${ }^{18}$ Therefore, the controversy between the results of the previously mentioned studies may be related to the diversity in methods and participants of studies and also the reference databases used by the DXA systems.

One of the strengths of our study was the considerable age-, sex- and physical activity-matched sample size (PPI users and non-users). In comparison with other studies, the other strength of our research was appropriate inclusion and exclusion criteria of both groups for restriction of effects of different confounding factors on bone density. Also, in this study we compared the bone density by analyzing both the BMC levels as a quantitative measure and T-scores as a semiquantitative measure between PPI users and non-users. But, our research had an important limitation. We were unable to measure and compare the metabolic bone markers between study groups due to their high cost. Individual foods or nutrients can be a confounding variable but was not assessed in this study. In our study physical activity was classified into 3 groups based on a simple questionnaire. For further validation, a standard questionnaire can be used to evaluate physical activity in similar future studies.

\section{Conclusion}

This study showed that long-term use of PPIs is associated with lower BMC and higher rate of osteopenia/osteoporosis. However, more studies with longitudinal evaluation can be performed to clarify this causal relationship. Until then it is advised not to overuse PPIs because of the possible increase in osteoporosis and the risk of fractures. We also recommend using the BMC levels as a quantitative measure in addition to T-score in analysis and reporting similar studies. As the world's population ages and the prevalence of both acid-related gastrointestinal disorders and osteoporosis increases, clarification of the effects of PPIs on bone density is urgently needed.

\section{Acknowledgments}

We would like to thank the vice chancellor for research at Shiraz University of Medical Sciences, Shiraz, Iran for financial support (92-01-13-5648). We also appreciate the help and support of the personnel at the Endocrine and Metabolism Research Center and the Gastroenterohepatology Research Center at Shiraz University of Medical Sciences. We also appreciate the help and support of the Center for
Development of Clinical Research of Nemazee Hospital for editorial assistance.

\section{Disclosure}

The authors report no conflicts of interest in this work.

\section{References}

1. Rotman SR, Bishop TF. Proton pump inhibitor use in the U.S. ambulatory setting, 2002-2009. PLoS One. 2013;8(2):e56060. doi:10.1371/journal.pone. 0056060

2. Lanza FL, Chan FK, Quigley EM. Guidelines for prevention of NSAID-related ulcer complications. Am J Gastroenterol. 2009;104 (3):728-738. doi:10.1038/ajg.2009.115

3. Freedberg DE, Kim LS, Yang YX, Risks T. Benefits of long-term use of proton pump inhibitors: expert review and best practice advice from the American Gastroenterological Association. Gastroenterology. 2017;152(4):706-715. doi:10.1053/j.gastro.2017.01.031

4. Kaye JA, Jick H. Proton pump inhibitor use and risk of hip fractures in patients without major risk factors. Pharmacotherapy. 2008;28 (8):951-959. doi:10.1592/phco.28.8.951

5. Ozdil K, Kahraman R, Sahin A, et al. Bone density in proton pump inhibitors users: a prospective study. Rheumatol Int. 2013;33 (9):2255-2260. doi:10.1007/s00296-013-2709-0

6. Targownik LE, Goertzen AL, Luo Y, Leslie WD. Long-term proton pump inhibitor use is not associated with changes in bone strength and structure. Am J Gastroenterol. 2017;112(1):95-101. doi:10.1038/ ajg.2016.481

7. Targownik LE, Leslie WD, Davison KS, et al. The relationship between proton pump inhibitor use and longitudinal change in bone mineral density: a population-based study [corrected] from the Canadian Multicentre Osteoporosis Study (CaMos). Am $J$ Gastroenterol. 2012;107(9):1361-1369. doi:10.1038/ajg.2012.200

8. Lai SW, Lin CL, Liao KF. Proton pump inhibitors therapy and the risk of major osteoporotic non hip fractures in older adults in Taiwan. Eur J Gastroenterol Hepatol. 2019;31(2):272-273. doi:10.1097/ MEG.0000000000001312

9. Moayyedi P, Eikelboom JW, Bosch J, et al. Safety of proton pump inhibitors based on a large, multi-year, randomized trial of patients receiving rivaroxaban or aspirin. Gastroenterology. 2019;157(3):682691. doi:10.1053/j.gastro.2019.05.056

10. Laine L. Proton pump inhibitors and bone fractures? Am J Gastroenterol. 2009;104 Suppl 2:S21-6. doi:10.1038/ajg.2009.48

11. Ngamruengphong S, Leontiadis GI, Radhi S, Dentino A, Nugent K. Proton pump inhibitors and risk of fracture: a systematic review and meta-analysis of observational studies. Am J Gastroenterol. 2011;106 (7):1209-18; quiz 19. doi:10.1038/ajg.2011.113

12. Khalili H, Huang ES, Jacobson BC, et al. Use of proton pump inhibitors and risk of hip fracture in relation to dietary and lifestyle factors: a prospective cohort study. BMJ. 2012;344:e372. doi:10.1136/bmj.e372

13. Adachi Y, Shiota E, Matsumata T, et al. Bone mineral density in patients taking H2-receptor antagonist. Calcif Tissue Int. 1998;62 (4):283-285. doi:10.1007/s002239900431

14. Solomon DH, Diem SJ, Ruppert K, et al. Bone mineral density changes among women initiating proton pump inhibitors or $\mathrm{H} 2$ receptor antagonists: a SWAN cohort study. J Bone Miner Res. 2015;30(2):232-239. doi:10.1002/jbmr.2344

15. Hansen KE, Nieves JW, Nudurupati S, Metz DC, Perez MC. Dexlansoprazole and esomeprazole do not affect bone homeostasis in healthy postmenopausal women. Gastroenterology. 2019;156 (4):926-934. doi:10.1053/j.gastro.2018.11.023

16. Kanis JA, McCloskey EV, Johansson H, et al. A reference standard for the description of osteoporosis. Bone. 2008;42(3):467. doi:10.1016/j. bone.2007.11.001 
17. Schousboe JT, Shepherd JA, Bilezikian JP, Baim S. Executive summary of the 2013 ISCD position development conference on bone densitometry. JCD. 2013;16(4):455-467. doi:10.1016/j.jocd.2013.08. 004
18. Looker AC, Melton LJ 3rd, Borrud LG, Shepherd JA. Changes in femur neck bone density in US adults between 1988-1994 and 2005-2008: demographic patterns and possible determinants. Osteoporos Int. 2012;23(2):771-780. doi:10.1007/s00198-011-1623-0

\section{Publish your work in this journal}

Risk Management and Healthcare Policy is an international, peerreviewed, open access journal focusing on all aspects of public health, policy, and preventative measures to promote good health and improve morbidity and mortality in the population. The journa welcomes submitted papers covering original research, basic science, clinical \& epidemiological studies, reviews and evaluations, guidelines, expert opinion and commentary, case reports and extended reports. The manuscript management system is completely online and includes a very quick and fair peer-review system, which is all easy to use. Visit http://www.dovepress.com/testimonials.php to read real quotes from published authors.

Submit your manuscript here: https://www.dovepress.com/risk-management-and-healthcare-policy-journal 